\title{
NEITHER FRIEND NOR ENEMY: PLANNING, AMBIVALENCE AND THE INVALIDATION OF URBAN INFORMALITY IN ZIMBABWE
}

\author{
Amin Y Kamete \\ University of Glasgow \\ ARTICLE DETAILS AND LINK \\ Kamete, A.Y. (2017) Neither friend nor enemy: Planning, ambivalence and the invalidation of urban \\ informality in Zimbabwe. Urban Studies (Forthcoming) \\ (c) 2017. This manuscript version is made available under the CC-BY-NC-ND 4.0 license \\ http://creativecommons.org/licenses/by-nc-nd/4.0/
}

\begin{abstract}
Planning relies on the strict classification and disposition of things in space. Intended to establish and maintain order, planning's classifying practices are reinforced by binarisms that revolve around legality/illegality. The article deploys Bauman's notion of the 'stranger' to recast hostility to informality as a symptom of antipathy against strangerhood and ambivalence. Drawing from qualitative research in urban Zimbabwe, I posit that because informality cannot be pigeonholed as either 'friend' or 'enemy', it instils a sense of unease in planners. I argue that this is a failure of the pursuit of order through binary antagonisms and contend that fixation with binarisms spawns 'spatial undecidables' and fuels resentment against informality. I propose that the notion of strangerhood complements and extends the concept of 'gray spacing'.
\end{abstract}

\section{Keywords}

planning, informality, Zimbabwe, ambivalence, strangerhood, binary antagonisms, spatial undecidables

\section{'NO SITTING ON IMAGINARY FENCES'}

As we concluded a conversation on urban informality in Harare, Zimbabwe, Principal Planner W (PPW) gave what he dubbed 'a live illustration'. He cleared his neat desk and placed my clipboard at one end of the table, and a folder at the other end. Pointing at his handiwork, he explained,

These are the two alternatives we have in urban planning, viz., a choice between legal order and illegal disorder $[s i c] . .$. As expert professionals, we planners reflect logical categories recognised in society. In planning, every single thing or activity must be put in one of the two categories, viz., legal versus illegal, which means order versus disorder. 
He darted across the room to a cluttered bookcase and grabbed a disposable tumbler containing an assortment of coins, staples and paper clips. Emptying the contents onto the table, he spread them in the space between the clipboard and the folder. He explained, 'This amorphous mass is the so-called informal sector occupying an imaginary no-man's-land.'

Turning to Arnold, my research assistant, he asked, 'What do you call somebody who refuses to fit into any category?' He paused, indicating he needed an answer. A bewildered Arnold shifted uncomfortably and hesitantly responded, 'Err, is it misfit?' PPW tapped Arnold on the shoulder, saying:

That's right, son. Misfits.... Dangerous misfits. They choose not to fit into any recognised category.... [B]ut we can't allow that to happen, can we, really? Planning ... can't cope when anything or anyone sits on imaginary fences. It's either kuno [here] or $u k o$ [there]. Waiketa? [You get the point?].

As he spoke, he pushed the 'amorphous mass' first to the clipboard and then to the folder, leaving the space in between clear. He concluded, 'Planning says no to a fictitious no-man'sland. There is no grey area in planning.... Everything in its place.'

PPW's reference to misfits reflects 'prejudicial attitudes that are given form in the world through ... exclusionary institutions' such as planning (Garland-Thompson, 2001:591). This discussion happened in 2008. I did not think much of it until I replayed the recorded conversation in 2010. Intrigued, I extracted all instances where order/disorder, legal/illegal, formal/informal were mentioned. The fascinating results prompted me to ponder over these binary oppositions and how they were often appealed to in explaining, justifying or charting planning strategies.

At its most scientistic, planning relies on the strict categorisation and disposition of things in space. In the regulation of space, the basic categories revolve around legality/illegality. They serve as the template for regulation and criminalisation. Based on interviews with planners in Zimbabwe, this article discusses the inability of informality to fit into planning's binarisms. I argue that because informality cannot be pigeonholed in either of the two categories of 'friend' and 'enemy', it instils a sense of unease in technocrats. Using Bauman's figure of the stranger, I recast endless attempts to suppress informality as a symptom of hostility towards those who do not fit within binary antagonisms. Interpreting this as a failure of the order modernity is devoted to achieving through binarisms, I contend that as long as there is a single-minded 
devotion to order through binary schemes, informals will be (re)produced as 'spatial undecidables'. I argue for the acceptance of ambivalence and the embracing of informals as different Others. This article makes theoretical and empirical contributions on a theme that is hitherto unaddressed. Despite the centrality of naming/classifying in planning controls, there has been no engagement with strangerhood in planning research.

In the next section, I discuss planning's fixation with naming/classifying and the notion of the stranger, depicting strangerhood as an outcome of an obsession with binary oppositions as the basis for order. I then present and discuss the study, showing planners' portrayal of informality as strangerhood. Before concluding, I reflect on the empirical material and discuss the article's theoretical and empirical significance by among other things, juxtaposing it with Yiftachel's concept of 'gray spacing'.

\section{PLANNING, SPACE AND THE FIXATION WITH NAMING/CLASSIFYING}

Planning is the state's premier spatial technology of domination (Pile, 1997). The domination is accomplished through abstract space (Lefebvre, 1991), a product of 'representations of space' comprising 'the discursive regimes of theories, spatial and planning professions and expert knowledges which conceive of space' (Shields, undated). Lefebvre (1991:33) claims that these representations of space are "tied to the relations of production and to the "order" which those relations impose, and hence to knowledge, to signs, to codes, and to "frontal" relations'. They denote 'conceptualized space'- the space of spatial experts like planners (Lefebvre, 1991:38). According to Lefebvre (1991:38), these experts 'identify what is lived and what is perceived with what is conceived', thereby making this conceptualised space 'the dominant space in any society'. To achieve this domination, planners cut up urban spaces, meticulously naming and categorising them. By dint of this, the authorities determine "who or what is normal or what is abnormal, who or what is appropriate and who or what is inappropriate, and who or what can be conceived and who or what is inconceivable' (Amin and Thrift, 2002:105).

This bid to control space largely relies on classification, 'a basic ideological mechanism' (Cresswell, 1996:161). In planning practice, it is classification that primarily determines where things should be and what, how and when things should be there. Accordingly, concerning space and place, it is the order imposed by planning that limits 'when, where and how a thing shall be done' (Freud, 2004:38). Through this dominative mechanism, planning ultimately determines what is in place and out of place (Cresswell, 1996), and thence what is legal and illegal. For all their multiplicity and detail, planning controls fundamentally encapsulate this 
binary opposition in various permutations: permitted/forbidden legitimate/illegitimate, and so on. Spatially, one of the central functions of these binary antagonisms is to serve as the basis for criminalizing what is deemed to be out of place. The 'either/or logics of categorisation' (Pickering, 2001:209) are indispensable to planning's modernist conception of order, progress, betterment and wellbeing. However, oftentimes, this binarism faces challenges that subvert it, thanks to the figure of the stranger in the form of informality.

\section{The rise of the stranger}

Modernity, a regime uniquely devoted to order (Phelan, 2001:29), is characterised by the obsession to have 'everything neat and tidy; no mess, no matter out of place' (Hughes, 2002:571). Solid modernity and its successor, liquid modernity, are both typified by the need for order (Bauman, 2000; 2012). Order makes it possible to 'domesticate, categorize, and rationalize the world', making it 'controllable, predictable, and understandable' (Routledge, 2016). Order is required to annul contingency and uncertainty (Pickering, 2001:209) by imposing 'stability and predictability on an unpredictable and fluid social world' (Marotta, 2002:42). The unfettered devotion to order is simultaneously enabled by and triggers off acts of naming and classifying. Neatness, tidiness and order are facilitated by - and require - the crafting, elaboration and imposition of categories that lay the groundwork for determining what is out of place, where and when. Thus, as argued by Diprose (1993:4), order is 'constituted by social concepts which discourage difference, creativity and change'.

In its practices of categorizing and boundary setting, modernity engenders binary schemes such as legal/illegal, order/chaos, inside/outside, good/bad, proper/improper (Phelan 2001). Any binarism splits the world into two: 'entities that answer to the name [and] all the rest that do not' (Bauman 1991:2). It is these schemes of binary opposites that inevitably (re)produce 'strangers' (Balibar, 2006).

Naming and classifying are indispensable to the conception, imposition and maintenance of order. Bauman (1991:2) observes that this 'naming/classifying function'

strives to achieve ... a sort of commodious filing cabinet that contains all the files that contain all the items that the world contains — but confines each file to a separate place of its own.... It is the non-violability of such a filing cabinet that makes ambivalence unavoidable. 
In this binary scheme, an object can only belong to one and only one file. As PPW put it, 'there are no fences to sit on'.

The purpose of the naming/classifying function is to prevent ambivalence, 'the possibility of assigning an object or an event to more than one category' (Bauman, 1991:1). Bauman (1991:244-5) graphically portrays ambivalence as 'a situation with no decidable solution, with no foolproof choice, no unreflective knowledge of "how to go on". To practitioners, ambivalence is a horrifying situation; it leads to paralysis of action. To forestall this appalling situation, the naming/classifying function must meet three conditions: neatness of the division between classes; precision of definitional boundaries; and unambiguity in the assignment of entities to classes (Bauman, 1991).

The primary binary that Bauman discusses at length is that between 'friends' and 'enemies'. The two 'stand in an opposition to each other' (Bauman, 1991:53). Each is what the other is not, with the enemies being 'the negativity to the friends' positivity' (p. 53). However, contrary to the aspirations of those who control the classification and assignment - and it is always 'friends' - the friend/enemy antagonism can never contain the whole social world because 'any binary scheme generates social undecidables' (Phelan, 2001:29). Predictably, the friend/enemy binarism spawns a social undecidable: the stranger. According to Bauman (1991:55), the stranger rebels 'against the cosy antagonism ... of friends and enemies'. As the bearer and embodiment of incongruity (Bauman, 1991:61), the stranger instantiates disruption and ambiguity.

\section{The consequences of strangerhood}

For this reason, the stranger is dangerous because 'the threat he [sic] carries is more horrifying than that which one can fear from the enemy' (Bauman, 1991:55). Whereas enemies are clearly the other - 'not like us' - and can be kept at bay, identified and acted upon, strangers, who are not like us, are our neighbours (Beck, 1996:382). That is the 'particular provocation of the stranger' (Phelan, 2001:29): both being and not being us. Paradoxically, the ambivalence whose prevention is the purpose of the naming/classifying function inevitably emerges as its product. As bearers of this ambivalence, strangers subvert modernity's 'natural' boundaries and borders, and in the process, present a challenge to the 'ontological security' (Giddens, 1990) ${ }^{1}$ provided by neat and tidy categories. They undermine 'the confidence or trust we have in the world around us' (Noble, 2005:113). Strangers are therefore the ultimate undecidables. According to Bauman (1991:56): 
Undecidables are all neither/nor; which is to say that they militate against the either/or. Their underdetermination is their potency: because they are nothing, they may be all. They put paid to the ordering power of the opposition, and so to the ordering power of the narrators of the opposition. Oppositions enable knowledge and action; undecidables paralyse them.

Whereas appropriate action can be directed at enemies because they are known to be such, strangers induce confusion, anxiety, and ultimately, paralysis.

The paralysis stems from the stranger's unamenability to knowledge. Modernity's rationalistic tendencies rely on knowledge. The rational decisions of technocrats represent the translation of this knowledge to action. It is difficult to act in the absence of knowledge. Thoroughly imbued with ambivalence, the stranger is the ultimate unknown and unknowable. It is little wonder that modernity cannot countenance ambivalence. The penchant for order cannot tolerate paralysis of action. Therein lies the roots of the dark side of modernism demonstrated in planning's sinister side (Yiftachel, 2000; Kamete, 2008).

This explains the array of responses comprising inclusionary and exclusionary practices - all of them attempts to neutralise and/or eradicate the stranger. Bauman insists that both solid and liquid modernity depend on authorities acting to both include and exclude strangers (Bauman and Obirek, 2015). Borrowing from Levi-Strauss's critical distinction between strategies of social domination, Bauman discusses two principal responses to strangerhood: anthropophagic and anthropoemic (Bauman, 1995:179-80). Anthropophagic responses entail assimilation and incorporation. The friends 'eat up, devour and digest ... the strangers ... hoping to ... absorb them, make them their own' (Bauman, 1995:179). The dominant order sucks in strangers 'devour[ing] them to annihilate them, making them metaphorically indistinguishable from the body of the existing organization' (Clegg, 2008:438). Conversely, anthropoemic responses involve exclusion - vomiting out strangers. According to Bauman (1995:180), the friends 'throw the carriers of danger up ... [and] keep them out of society's bounds'. In contrast to the annihilation of difference that characterises anthropophagic strategies, anthropoemic strategies respond to difference by dismembering and spitting out the risk (Clegg, 2008:438). Behind anthropophagic strategies is the desire for inclusion powered by the 'urge to convert' the Other, whereas anthropoemic strategies are fuelled by the 'urge to exclude', to keep the Other at bay (Bauman and Obirek, 2015:27). 
In his latter writings, Bauman extended the notion of strangerhood to his critique of capitalism, globalisation and consumerism and their production of non-voluntary travellers, flawed consumers, and undecidables: the 'vagabonds' and 'wasted lives' who are liquid modernity's strangers (Bauman, 1998, 2002, 2004; Månsson, 2008). He maintains that these strangers threaten the boundaries that the ordering process seeks to protect (Marotta, 2002). In his last writings, Bauman emphasised how strangers' unknowability generates the inability 'to read properly their gambits and compose ... fitting responses' (2016:9). Linking paralysis of action to fear and anxiety, he insists that 'the ignorance of how to go on, how to deal with a situation not of our making and not under our control, is a major cause of anxiety and fear' (2016:9).

\section{Strangerhood and planning scholarship}

There is no explicit engagement with naming/classifying and strangerhood in planning literature. The closest planning scholarship gets to this is Yiftachel's concept of 'gray spacing' that links informality to a 'politics of un-recognition' (Yiftachel, 2009a:92). Yiftachel (2009a, 2009b) highlights the failure of 'legality' and 'illegality' to accommodate informality, resulting in the production of gray spaces which are 'developments, enclaves, populations and transactions positioned in a permanent temporariness between legality and illegality' (Legrand and Yiftachel, 2014:206). This resonates with the stranger's liminality. Implying anthropoemic and anthropophagic approaches, Yiftachel (2009a:88) observes that informalities are "positioned between the "whiteness" of legality/approval/safety, and the "blackness" of eviction/destruction/death'. Implying planning's binary antagonisms, Avni and Yiftachel (2014:487) assert that "the process of "gray spacing" has blurred the neat dichotomies between legal and illegal, citizen and alien, permanent and temporary'. 'Gray spacing' is a pioneering notion. However, it does not explicitly engage modernistic obsessions with naming/classifying per se, but with its consequences. This article bridges this gap.

\section{PLANNING, INFORMALITY AND STRANGERHOOD IN URBAN ZIMBABWE}

\section{Background}

In Zimbabwe, the authorities' attitude to informality is contradictory and ambiguous (Kamete, 2008). They openly profess support for the informal sector, declaring that the government 'recognizes and continues to promote the role of the informal sector in the economy' (GoZ, 2005:8). Significantly, the Ministry of Youth Development and Employment Creation 
(MYDEC), maintains that its role is 'to lobby for the recognition of ... micro enterprises, the informal sector and cooperatives in ... government policy' (MYDEC, undated).

Notwithstanding these professions, in their relentless quest for modern cities, the authorities have consistently adopted heavy-handed approaches to informality. Since independence, they have persistently tried to 'swallow' informal work by assimilating it into small businesses farremoved from existing informalities, which they perceive as pre-modern or anti-modern (Kamete, 2013). They espouse small- and medium-scale enterprises (SMEs) cleansed of troublesome traits of informality. Their vision of the city has no room for ambulant informals who occupy and use space in contravention of planning controls. The favoured SMEs are expected to operate 'within the confines of the law' in matters like land use, registration, and taxation (GoZ, 2005:27).

The nature of post-independence state agencies mandated to govern informal livelihoods reveals the state's obsession with formalizing informality (Kamete, 2008). Informal businesses have been within the remit of ministries such as 'Cooperative Development', 'Employment Creation', and lately, 'Small and Medium Enterprises Development' (MSMED). Significantly, MSMED's mission statement emphasises creating 'an enabling environment that promotes vibrant small and medium enterprises' (MSMED, 2007; my emphasis). There is no reference to informality in the ministry's vision, mission statement and overall functions. Notably, in 2005, the ministry vociferously supported 'Operation Murambatsvina/Restore Order', the colossal urban clean-up operation (Kamete, 2009) that decimated informality. Further, the informal sector is governed by the Co-operative Societies Act which has no provision for informality. It focuses on enterprises that mimic formal businesses and, in line with modernisation perspectives, are expected to graduate to full-blown formal businesses (see MYDEC, undated).

\section{The study}

The article draws on qualitative research with planners in Harare. The in-depth interviews and two focus groups were conducted in December 2010. ${ }^{2}$ Twelve planners from local government, central government, the private sector and academia agreed to participate in the in-depth interviews and focus group (see Table 1). The research centred on urban informality with special emphasis on planners' perceptions, understanding, attitude and interpretation regarding such aspects as legality and order. The focus was on the categorisation and assignment of urban informal livelihoods, where and why. ${ }^{3}$ 
Table 1. Details of participants and interviews

\begin{tabular}{lll}
\hline Planner ID & Institutional affiliation & Date interviewed \\
\hline Principal Planner W $(\mathrm{PPW})$ & Central government & 22 January 2008 \\
$\mathrm{Mr} \mathrm{B}$ & Central government & 21 December 2010 \\
$\mathrm{Mr} \mathrm{D}$ & Private sector & 13 December 2010 \\
$\mathrm{Mrs} \mathrm{G}$ & Local government & 14 December 2010 \\
$\mathrm{Mr} \mathrm{L}$ & Central government & 16 December 2010 \\
$\mathrm{Mrs} \mathrm{Q}$ & Central government & 19 December 2010 \\
$\mathrm{Mr} \mathrm{R}$ & Private sector/academia & 13 December 2010 \\
$\mathrm{Ms} \mathrm{S}$ & Local government & 15 December 2010 \\
$\mathrm{Mr} \mathrm{T}$ & Local government & 16 December 2010 \\
$\mathrm{Mr} \mathrm{V}$ & Local government & 17 December 2010 \\
$\mathrm{Mr} \mathrm{X}$ & Private sector & 14 December 2010 \\
$\mathrm{Mr} \mathrm{Y}$ & Local government & 20 December 2010 \\
$\mathrm{Ms} \mathrm{Z}$ & Central government & 22 December 2010 \\
\hline
\end{tabular}

This is a study of professional planners in the state-directed statutory planning system in contemporary Zimbabwe during a time of political and economic crises (Kamete, 2009). Although non-formal/non-statutory forms of planning exist, statutory planning is the planning that is authorised and empowered by the state. In contrast to non-statutory forms of planning, statutory planning is about public control over private interests. Particularly in authoritarian states like Zimbabwe, statutory planning has a dark side (Yiftachel, 2000). It is this planning that informality encounters. The study is located within a particular historical, political, economic and social setting with an authoritarian state obsessed with order. It is about the perspectives of professional planners in a context where the regulatory and statutory framework reflects entrenched prejudice and resentment towards informality. Obviously, the perspectives of planners in the study are not necessarily all that shapes the governing of urban space. Other political and professional players are involved (Kamete, 2009). The article is about planners' views, not actual acts of inclusion/exclusion. It illuminates standpoints that explain the status and handling of urban informality.

\section{Informality as strangerhood in urban Zimbabwe}

The classification and assignment of things and practices is integral to Zimbabwe's planning system, one of the toughest in Africa (Kamete, 2008). Like the British planning system it initially mimicked, the statutory and regulatory framework is awash with categories (Wekwete, 1988; Kamete, 1999). At the heart of the categories is a distinction between what is permitted and what is forbidden. Spawned by this originary binary are various binarisms, the principal one being legal/illegal. Endorsing what he described as the 'basic building block of planning regulation', $\mathrm{Mr} \mathrm{B}$, explained that 'guidance, clarity, certainty and practicality are what classification tools bless us [sic]'. To him classification makes it possible for 'planning to 
function and for planners to act, [for] decisive action is based on clearly dividing [sic] what is lawful from what is unlawful'. This, as elaborated by Ms Z, is the 'only way for averting paralysis and chaos because it facilitates efficient decision-making and timeous action'.

Contemptuously dismissing "funny, crazy imaginary terms like "extra-legality" and "semilegality"', Mr D quipped that these were 'theoretical weird inventions' whose only value was that 'they can be typed on a computer and provoke debate'. In the real world, where planning is about spatial propriety, where 'action must be taken at a routine everyday level [sic]' (Mrs $\mathrm{Q})$, it is necessary to 'position order versus disorder, legality versus illegality' (Mr D). $\mathrm{Mr} \mathrm{B}$ strongly believed that 'in this practice-orientated reality, weird in-betweeners [sic] don't and shouldn't exist'.

To planners, the basic binary opposition is what $\mathrm{Mr} \mathrm{T}$ summarised as 'acceptable and unacceptable ... meaning what is stipulated as legal and what is illegal'. Through this distinction, 'crime is clearly codified and law-breakers are easy to pinpoint and deal with' (Mrs G). According to Mr L, the clarity brought by the legal/illegal distinction means that "whether you are a planner, a policeman, and whatnot ... you can jealously protect the public interest by identifying and fighting deviance and crime'. In the final analysis, 'having two clear compartments of the legal and illegal illuminates issues of order and disorder', allowing planners to avoid being confronted with 'ambiguousness and uncertainty at a routine everyday level [sic]' (Mrs Q). True to the precepts of modernity, the clear compartmentalisation of land uses into the permitted and the outlawed enables the planning system to 'smoke out and decisively discard enemies of order and progress whenever, however and wherever they appear' (Mr R).

On whether the informal sector was legal or illegal, Ms S explained:

You see, this is exactly ... their problem. In the scheme of things, you are either this side or that side, here or there. They cannot be somewhere else.... Legal and illegal that is all there is; not semi-legal and some of those words you concoct - what is it, extra-legal? In actual planning, there shouldn't be such confusing nonsensities. So, yes, by any stretch of imagination, to me informal should be illegal.

Describing something as 'informal' was according to Mr B 'tantamount to building confusion ... like the confusion at the Tower of Babylon [sic]'. ${ }^{4}$ To $\mathrm{Mr} \mathrm{B}$, as a label, informality was 'only as good as a name with no actionability $[$ sic]'. He went on: 
Correct me if I am wrong. In living things there are two kingdoms: the animal kingdom and the plant kingdom. I don't know of a third... Ndiudze [Tell me], if there is a war between plants and animals whether you are a person, a donkey or a baobab tree, you will have to be in one of the kingdoms and you will need to meet the criteria for that kingdom, because these are the options of the moment. So, in the world of planning you are either legal or illegal, ... criminal or legit, or as you say, friend or enemy. Your people in the informal sector can't just come up with a chipoko [phantom] kingdom that doesn't exist. They must choose, so we know what to do with them.

Pressed to explain how the strangers could choose a side, $\mathrm{Mr} \mathrm{B}$ insisted that 'there are criteria and standards that have to be met and those empowered to do so will decide and verify your claims to belong'. The choice of side is not the stranger's to make after all. It is technocratic agents of the dominant order that make the choice and assign entities to a category. This resonates with Bauman's (1991:53) assertion that the right to define is asymmetrical, as 'it is the friends who define the enemies'.

The planners underscored what informals, in particular vendors, do not share with 'decent, lawful hardworking enterprises' (Mrs Q). This was lucidly enunciated by Mr Y:

These ones are not like decent businesses; there is no resemblance. This doesn't imply they are simply unidentical [sic] twins or another sibling or relative. There is no resemblance, ... no blood family ties. There can never be family ties... There are no genetic commonalities. Yes, vatorwa, mabvakure [strangers, aliens].

There are four conclusions that can be drawn from the preceding perspectives. First, binarisms are necessary for order. Second, there is no room for a middle ground. Thirdly, the duality and its clarity enable state-directed planning 'to execute its mandate swiftly, decisively and efficiently' (Mrs G). Finally, despite Mr B's insistence that strangers must choose a side, it is 'friends' - the hegemonic planning system - that delineate the categories.

Is informality similar to the criminal underworld? Mr V responded, 'No, no, no, that isn't the case. You, see this is the problem'. This indeed was the problem. Ms Z, who bragged about having crafted 'some crucial planning policies', stressed that it was 'a mammoth task to pin down this sector'. And this, according to Mrs Q, is 'the source of the whole headache, ... a big everlasting inconvenience'. Said Mrs G,

Thieves, rapists, and murderers - we can identify them. They don't pretend to be anything else. And they operate nicodemously [secretly], out of sight, under cover of darkness.... 
These ones [informals] vanedzungu [they are daring]. They operate right under our noses, and we don't know what to do with them.... I say mbavha dziri nani [thieves are better]. You know them and can deal with them pakarepo [there and then].

This was echoed by Mr B, who expressed his 'immense worry and dismay' at having to deal with 'something that cannot be compartmentalised in any one colour code, because it has many colours rwaivhi-style [chameleon-style]'. Illustrating the 'huge difficulty inflicted by this ambiguity', Ms S asked:

How do you classify someone owning a licence, but operating without a lease? Or someone who owns a house legally classified as residential but uses it for business purposes for which she has a licence? Semi-legal? Half-criminal? There are no such ambiguous words and classes in planning law. Yeah. There shouldn't be.

To $\mathrm{Mr} \mathrm{V}$, this is precisely the problem, 'the refusal to fit [into] existing standard categories for correct spatial ordering of cities'. Therein lies the 'big threat and unadulterated dangerousness of these people' (Mr B): the inability to be pigeonholed and contained in conventional binary antagonisms.

Part of the 'dangerousness' identified by $\mathrm{Mr} \mathrm{B}$ is that the refusal to belong to 'standard categories', amounts to 'an open-air challenge to scientific knowledge'. Mr B asked, 'How can we practice when we cannot use our expertise, [when] knowledge becomes unusable?' This echoes Bauman's (1991:53) assertion that the friend/enemy rift is necessary for knowledge and action to 'chime in unison' as knowledge informs action and action confirms the truth of the action. Informality disrupts this unison.

What then are people for whom informality is a way of life? Mr Y retorted, 'You tell me. What I know is they crop up where we don't want them and grow roots'. That informality 'crops up' where it is unwanted was a point every planner emphasised. This is not surprising; planners are 'spatial technicians, ... land use custodians'. (Mr V). To planners, informals are 'technically always out of place' (Mr R). This means they are 'dirt' or 'filth' - terms that gained notoriety during 'Operation Murambatsvina/Restore Order' in 2005 (Potts, 2006; Kamete, 2007).

In Ms Z's view, anything that is 'where it shouldn't be is filth, nothing but filth; period'. Emphasising that he made 'no stupid ... apologies for telling it like it actually is', Mr V, insisted, 'Anything that can't be filed in the existing filing system belongs to the trashcan because itsvina [it's filth]'. What makes informality a particularly 'virulent kind of filth' is that 
it 'stubbornly continues abusing planned spaces' (Mr T) by subverting the hallowed principles of 'legally prescribed uses and ownership'.

Another thing that particularly worried planners was the seeming permanence and resilience of informality. When informals 'invade space, they always stubbornly stay and refuse to go' (Mr D). Comparing informal traders to what he called 'outright criminals' Ms S pointed out:

I wouldn't lose sleep if these people were just like morning fog passing through town.... I can say I am less worried about thieves because they come and go. They don't claim territory vobva vatodzika midzi [and grow roots]. But these ones, they stay. Vatoramba zvokushaikwa [They have refused to disappear].

Summarising what he called the 'meat of the whole terrible situation', Mr X mused, 'instead of just being a passing event, it has become a permanent feature. Instead of being out there, it is right here muberere medu chaimoimo [on our doorstep]'. And the strangers were multiplying by the day. PPW put it metaphorically: Instead of being 'like punctuation marks on a page ... [informals] have become like the actual letters on the page'. Here we see a stranger who has become a neighbour (Beck, 1996; Sandercock, 2000), decided to stay, and keeps on multiplying.

On their feelings about the strangerhood embodied in informality, it was clear that it made planners apprehensive. Ms X labelled it 'a terrible nightmare', while Mr L described the thought of engaging it as 'always sending chills down my spine'. It was 'that lingering and persistent uncertainty' (Mr L) that was the 'source of painful trepidation to technocrats' (Mr Z). Being 'something of a very, very unknown quantity' (Mrs G), this stranger was not 'amenable to rational technical intervention' (Mr R). This was 'complicated by stupid political indecision, which permeated to planning [sic]' (Ms Q). This double paralysis - political and technical - is to Mrs Q, the reason for the persistence of vending, street trading, and home-based enterprises. According to $\mathrm{Mr} \mathrm{R}$, the lack of 'effective and decisive action is symptom[matic] of the paralyzation that emanates from the unknownness [sic] of this problem, the absence of proper tools, and the refusal of the [informal] sector to respond to current strategic measures'.

\section{ON URBAN INFORMALITY AS STRANGERHOOD}

The study yields refreshing insights into the status of informality vis-à-vis urban planning. Zimbabwe's planning system is steeped in modernity. The system, which initially closely modelled itself on planning in the metropole, has never wavered from modernist preoccupations with order and normalisation. Its naming and classifying function, as instantiated in forward 
planning and development control, remains a potent tool for establishing order, maintaining it, and quelling contravention. Typical of modern culture, the system is 'desperate for order, quick to stifle transgression, uncomfortable with difference' (Hughes, 2002:571).

To what extent is Bauman's notion of the stranger applicable to planning in Zimbabwe? Bauman's theorisation is a sociological formulation focusing on modern culture in western societies (Rumford, 2015). This raises questions about context, discipline and intellectual heritage. Bauman's modernity refers to the period that started in Western Europe in the 17th century (Månsson, 2008). In matters of applicability, where modernity started is not the issue, but what it implies. Though modernity can be traced back to Western European society and culture, it became a global trend (Berman, 1988). It implies 'a series of profound cultural, economic and administrative rationalizations and differentiations of the social world' (Månsson, 2008:160). Zimbabwe's planning system models itself on these 'rationalizations and differentiations' (Kamete, 2013). It also espouses modernism, which operates within but is distinct from modernity. Intellectually (and culturally), if we take modernism as referring to the visions and values that emphasise the power of humans to change the world by creating, improving and reshaping their environment using scientific knowledge (Berman, 1988:16), then it snugly fits Zimbabwe's planning system (Kamete, 2013).

Can 'the stranger' and 'the informal' be so neatly equated? Bauman consistently deploys the notion of stranger to unpack the thinking behind estrangement, marginalisation and exclusion (Månsson, 2008). Several scholars have productively expanded the notion to encompass 'social undecidables' based on various themes such as sexuality (Moran and Skeggs, 2004), disability (Hughes, 2010), citizenship (Rundell, 2004) and leisure (Blackshaw, 2003). This demonstrates the notion's malleability. This article extends this formulation to informality. Bauman has never referred to informality when writing about strangers. However, the undecidability associated with strangerhood is applicable to informality. Although Bauman's work has no explicit connection to informality, 'his sensitivity to modern patterns of exclusion and 'othering' provides ... a useful template' (Hughes, 2002:571) that helps us productively (re)conceptualise the relationship between planning, modernity and informality. To the extent that they threaten the 'stability and coherence of the social order' (Marotta, 2002:38), and are liminal outcasts ‘constantly kept at bay’ by the statutory planning system (Månsson, 2008:155), informals count as 'strangers'. 
In governing space, planning's dualistic division of entities and activities has created categories that correspond to the friend/enemy binarism (Bauman, 1990; 1991). However, like elsewhere, this naming and classifying function has been exposed as not being able to contain the whole world (Phelan, 2001). It has spawned ambivalence in the form of informals - 'spatial undecidables' inevitably (re)produced in the interstices between the dualistic oppositions.

These 'spatial undecidables' are people for whom informality is a way of life. Neither criminal nor - from the standpoint of state-directed planning - respectable citizens, they are strangers who have rebelled 'against the cosy antagonism ... of friends and enemies' (Bauman, 1991:55). They have 'open[ed] up the politics of representation to the poetics of transgression' (Pickering, 2001:217). What informality opposes is 'opposition itself' (Bauman, 1990:53), in particular, the opposition between legitimate/illegitimate and inside/outside. By bringing the outside into the inside, they have disrupted 'seemingly natural boundaries and boarders' (Phelan, 2001:29), thereby inducing anxiety, uncertainty and ontological insecurity in planners. Where there should be clear oppositions that enable knowledge and action, the undecidables threaten to bring paralysis (Bauman, 1991:56).

By their very existence, these strangers have done the unforgivable: questioning 'one of the fundamental binary oppositions of social interaction, that between friends and enemies' (Järvinen, 2002:217). Whereas friends and enemies (formal businesses and the criminal underworld, for example) stand in direct opposition to each other, informals rebel against this dual system. They have brought 'the outside into the inside, the negative into the positive, the alien into the well-known' (Järvinen, 2002:217). The planners' uneasiness and hostility are perhaps understandable. By their 'sheer presence, which does not fit easily into any of the established categories', informals

deny the very validity of the accepted oppositions. They belie the oppositions' 'natural' character, expose their arbitrariness, lay bare their fragility. They show the divisions for what they indeed are: imaginary lines which can be crossed or redrawn (Bauman, 1990:54).

And redrawn the imaginary lines they have, thus bringing 'the outside into the inside, and poison[ing] the comfort of order with suspicion of chaos' (Bauman, 1991:56). These neither/nor beings have doggedly wreaked havoc on planning's cherished either/or constructions (Bauman, 1991:56). It is this underdetermination that is the potency of these undecidables. Their being nothing carries the horrifying possibility of them being all: the ultimate ambivalence that generates paralysis. Unsurprisingly, planners are not amused by such 
ambiguous labels as 'semi-legal' and 'extralegal'. If recognised, these ambivalent terms would bring chaos to planning's hegemonic order. In modernist planning, 'chaos is the arch-enemy of a rationalising order that demands homogeneity, clarity and perspective' (Hughes, 2002:572). Most chillingly, the resultant ambivalence would compromise the basis for rational action.

From the standpoint of the rationalist modernity cherished by planners, as 'bearer and embodiment of incongruity' (Bauman, 1991:61), informality 'resist[s] the triumph of reason'. So, it is rejected or forgotten (Touraine, 1995:201). This powerful rejection has found expression in anthropoemic and anthropophagic strategies (Bauman, 1995:179-80). These represent an attempt to restore order, to banish 'impurity', to put everything back in its proper place, in order to avoid the spectre of dirt or filth (Douglas, 2002; Cresswell, 1996). Order demands the suppression of the middle ground - the troublesome and dangerous no-man's-land - that is the source and breeding ground of ambivalence.

What accounts for the prevalence and persistence of antagonism towards the stranger among planners? This can be partly attributed to the colonial legacy and planning education. The dualisms in planning law, planning schemes and development plans were inherited from the modernist colonial planning system (Njoh, 2006). Planning education has contributed to the perpetuation of the antagonism by continuing to espouse and reflect the dualisms. Be that as it may, to hastily attribute everything to planning education and the colonial legacy is to miss a crucial point: planners are comfortable with the dualisms. Planners are located within a given historical, political, social and economic setting. Their relationships to the situated political and economic dynamics in which they are entrenched is important. ${ }^{5}$ Their horror of multiplying 'spatial undecidables' should also be seen in the context of the wider national crisis in which planning functions. Through this crisis, 'friends' (formality) have dwindled and 'strangers' (informality) have become the norm. The expansion of strangerhood - interpreted by planners as defiance - is largely a reflection of a lack of alternatives.

While education, colonial legacy and context explain planners' hostility, it seems this animosity is useful to planning. It enables planners 'to evaluate and judge with certainty and to respond decisively to every phenomena $[s i c]$ in urban space' (Ms Z). Further, the potency of the binarisms in reproducing existing power configurations serves elite interests and promotes their modernist aspirations (Kamete, 2016). This convergence of bureaucratic operational convenience with elite interests has contributed to the entrenchment of dualistic antagonisms. 
Is the hostility exhibited by planners born of malice? I contend that the sentiments of planners betray not malice, but anxiety, fear, discomfort and horror. The strangers' central problem is ambivalence: a threat to planning's drive for order (Rumford, 2016). This induces fear of losing control and paralysis of action. What the planners betray is discomfort and anxiety resulting from the inability 'to read the situation properly and choose between alternative actions' (Bauman, 1991:1). It is the horror of being rendered impotent, of seeing cherished knowledge invalidated by the underdetermined stranger who stubbornly self-defines and eludes official definitions (Bauman, 1991:2).

\section{THEORETICAL AND EMPIRICAL CONTRIBUTIONS}

The article makes several key theoretical and empirical contributions. First, by connecting informality to strangerhood and ambivalence, the paper deploys Bauman's thought-provoking sociological formulation in a new context (global South) and field (informality and urban planning). Second, when it has become fashionable to view cities and informality from the standpoint of informals, activists and politicians, the article makes empirical contributions by presenting and dissecting the uncoloured perspectives of planners. In so doing, it exposes their trepidation and hostility towards informality, uniquely recasting it as fear of the stranger and arguing that this is not antagonism to informality per se, but to its resistance to pigeonholing. The article proposes a refreshing explanation for the handling of informality by going beyond simplistic notions of modernism and order. It singles out naming and classifying as the bedrock of planners' uneasiness and antipathy.

Third, theoretically and empirically, the article complements Yiftachel's concept of 'gray spacing' (Yiftachel, 2009a). Gray spaces can be equated to the middle ground occupied by the spatial undecidables - 'the non-position that exists in the space between given categories' (Månsson, 2005:160). As noted earlier, Yiftachel and others who have deployed his formulation do not explicitly engage the modernistic obsession with binarisms, but rather its consequences (Yiftachel, 2009a, 2009b; Sanyal, 2014; Jongh, 2015; Lutzoni, 2016). This article suggests that 'gray spaces' are a consequence of planning's naming/classifying function. Writings on 'gray spaces' emphasise their being 'regarded as unrecognized' (Yiftachel, 2015:730). This article provides deeper theoretical and empirical insights that could explain this 'un-recognition'. It suggests the stranger can never be recognised; doing so would be tantamount to bringing the outside into the inside (Bauman, 1991:56). The article posits that for planners, acknowledging informality - the embodiment of strangerhood - would be tantamount to embracing 
ambivalence. It would disrupt and invalidate the cherished binarisms, the knowledge on which they are based and the ontological security they provide.

Avni and Yiftachel (2014:487) argue that state authorities are involved in producing and maintaining 'gray spaces' (cf. Roy, 2009). The planners' aversion to the existence of 'the most vexing and disturbing middle ground' (Bauman 1995:180) between legality and illegality confirms this assertion, but with an important clarification. The palpable repugnance towards spatial undecidables suggests that the (re)production and persistence of 'gray spaces' is not intentional. Rather, this spawning of spatial undecidables is a consequence of naming and classifying. Further, Yiftachel (2009b:243; my emphasis) asserts that in the urban policy sphere, "gray spaces" are usually quietly tolerated, while subject to derogatory discourses about their putative "contamination", "criminality" and "danger" to the desired "order of things". The sentiments of planners confirm the existence of these derogatory discourses. However, this article questions whether what we see is urban policy quietly tolerating strangerhood ('gray spaces'). It suggests that the quiet toleration might not be what it seems; this might be paralysis of action generated by what planners see as a horrifying situation: ambivalence (Bauman 1991:244-5). This ambivalence-induced paralysis of techno-legal instruments explains why decisions on handling informality are frequently taken in the political sphere (Kamete, 2009).

\section{CONCLUSION}

Categorisation is key to the execution of planning's mandate in the governance of space. Given that planning's commitment to order is characterised by an attachment to dualistic oppositions, there is a case for deploying Bauman's formulations of strangerhood, ambivalence and the friend/enemy binary antagonism. This reframing of the obsession with naming/classifying yields helpful insights into hostility to urban informality. Seeing informality through the lens of strangerhood and ambivalence (re)produced by the friend/enemy binarism, provides a productive way to recast not only the emergence and persistence of 'gray spaces' of informality, but also crucially, the uneasiness of planners.

The voices of planners demonstrate that binarisms are instrumental to the conception, imposition and maintenance of order and the forestalling of chaos, 'the other of order and its pure negativity' (Bauman, 1991:7). Strangers that they are, informals defy this binarism, thereby opposing the 'opposition itself' (Bauman, 1990:54). As spatial undecidables, informals resist and disorganise the neatness of binary oppositions (Rumford, 2015:25). Their existence is a challenge to planning's drive for order. This explains the planners' unbridled animosity. 
As revealed in the planners' sentiments, at the heart of modernist planning is a strong commitment to 'a dream of purity' (Bauman, 1997:5), hence the persistence of 'a vision of order, a world clean and hygienic' (Hughes, 2002:573). In this schema, informality constitutes an impurity that needs to be banished, hence the ceaseless attempts to obliterate the troublesome middle ground. This explains the authorities' refusal to recognise informality as a category sui generis.

In its bid to sever, correct, exile and normalise difference, planning has constituted out of its artificial order, a bothersome stranger. The problem with a single-minded pursuit of purity is that it becomes a never-ending routine because of failure to keep up with changes in the world that planning seeks to order. Accordingly, as noted by Hughes (2002:573), 'purity must be continuously redefined and new purifying projects continuously invented'. This, asserts Bauman (1997:11), triggers a 'state of perpetual beginning [which] generates ever new "improved" targets of purity and with each new target cuts out new categories of "dirt" - an unheard-of dirt and an unprecedented dirt'. Consequently, as reflected in the voices of planners, 'order making now becomes indistinguishable from announcing ever new abnormalities, drawing ever new dividing lines, identifying and setting apart ever new strangers' (Bauman, 1997:11).

This might explain why the informal sector continues to be an unresolved issue in planning in the global South. It is evident in the endless (re)conceptualisation of informality: from dualist, to structuralist, to legalist, to illegalist approaches (Potts, 2008). All these approaches prescribe anthropophagic responses in the form of 'inclusion' or 'integration' as the panacea to the 'problem' of informality (Kamete, 2017). Planning's role as the custodian of space gives it a prominent position in these endless quests. That there has never been a conclusive resolution to this problem is symptomatic of the absence of a way to conceptualise, name, classify and respond to the stranger that is informality. On the part of planners, it is partly a symptom of the inability or refusal to become more reflexive about the stranger as a product of the modernist fixation with the creation, imposition and maintenance of an artificial order (Clegg, 2008:445) and of the inadequacy of the dualistic antagonisms to contain everything.

The only way to break this endless labour of naming and classifying is to recognise the inadequacy of binary antagonisms and take the 'strangers' for what they really are: neither 'friends' in the sense of being 'like us' nor enemies in the sense of being 'against us' (Bauman, 1991). This entails a willingness to embrace informality as a representation of itself 'instead of 
treating ... [it] as an unwanted peculiarity constantly out of place’ (Månsson, 2008:170). This would end attempts to forcibly fit this stranger into binarisms. This could enable planners to reinterpret strangerhood and the ambivalence of informality not as an existential threat, but as mere difference. It might lead to a realisation that 'the anxiety of strangers' should not be mistaken for or converted to 'the fear of enemies' (Segal, 1998:271). While it is not unusual to feel a certain 'discomfort of strangers' (Noble, 2005), this should not be taken to mean the permanent loss of ontological security. Rather, for reflective practitioners, this should, as Segal (1998:271) suggests, be 'an occasion for an existential philosophical education ... in which the resolute acceptance of strangerhood allows us to reflect on our taken-for-granted about the everyday'.

\section{ACKNOWLEDGEMENT}

I am grateful to Vanessa Watson and Ruth Harkin for being flexible during a particularly difficult time for me. I thank the supportive planners for their time and for relentlessly goading me to publish the study. I also thank the anonymous reviewers for their critical comments that significantly improved the argument.

\section{Notes}

${ }^{1}$ Giddens (1991:92) defines ontological security as 'the confidence that most human beings have in the continuity of their self-identity and in the constancy of the surrounding social and material environments of action'.

${ }^{2}$ As noted in the introduction, I became interested in this theme after listening to recordings of interviews from 2008.

${ }^{3}$ For scholarly works discussing the positioning of planners and planning in the political, institutional and structural conditions of contemporary Zimbabwe see Kamete (2009, 2016) and Potts (2006).

${ }^{4}$ He was probably referring to the biblical Tower of Babel in Genesis 11:1-9.

${ }^{5}$ See endnote 3 


\section{REFERENCES}

Amin A and Thrift N (2002) Cities: Reimagining the Urban. Cambridge: Polity.

Avni N and Yiftachel O (2014) The new divided city? Planning and 'gray space' between global north-west and south-east. In: Parnell S and Oldfield S (eds) The Routledge Handbook on Cities of the Global South. Abingdon: Routledge, pp. 487-505.

Bauman Z (1990) Thinking Sociologically. Oxford: Blackwell.

Bauman Z (1991) Modernity and Ambivalence. Cambridge: Polity.

Bauman Z (1995) Life in Fragments: Essays in Postmodern Moralities. Oxford: Blackwell.

Bauman Z (1997) Postmodernity and its Discontents. Cambridge: Polity.

Bauman Z (2002) Society under Siege. Cambridge: Polity.

Bauman Z (2012) Liquid Modernity. Cambridge: Polity

Bauman Z (2016). Strangers at Our Door. Cambridge: Polity.

Bauman Z and Obirek S (2015) Of God and Man. Cambridge: Polity.

Beck U (1996) How neighbors become Jews: the political construction of the stranger in an age of reflexive modernity. Constellations 2(3):378-396.

Berman M (1988) All That Is Solid Melts into Air: The Experience of Modernity. London: Penguin.

Blackshaw T (2003) Leisure Life: Myth, Masculinity and Modernity. London: Routledge.

Clegg S (2008) If people are strange, does organization make us normal? In: Barry D and Hansen H (eds) The Sage Handbook of New Approaches to Organization Studies. London: Sage, pp. 436-453.

Cresswell T (1996) In Place/Out of Place: Geography, Ideology and Transgression. Minneapolis: University of Minnesota Press.

Diprose R (1993) Nietzsche and the pathos of distance. In: Patton P (ed) Nietzsche, Feminism and Political Theory. Abingdon: Routledge, pp. 1-26. 
Douglas M (2002) Purity and Danger: An Analysis of Concepts of Pollution and Taboo. London: Routledge.

Freud S (2004) Civilization and Its Discontents. London: Penguin.

Giddens A (1990) The Consequences of Modernity. Stanford: Stanford University Press.

GoZ (Government of Zimbabwe) (2005) Response by Government of Zimbabwe to the Report by the UN Special Envoy on Operation Murambatsvina/Restore Order. Harare: Government Printer.

Hughes B (2002) Bauman's strangers: Impairment and the invalidation of disabled people in modern and post-modern cultures. Disability \& Society 17(5):571-584.

Järvinen M (2003) Negotiating strangerhood: Interviews with homeless immigrants in Copenhagen. Acta Sociologica 46(3):215-230.

Kamete AY (1999) Restrictive control of urban high-density housing in Zimbabwe:

Deregulation and challenges for urban design. Housing, Theory and Society 16(3):136-151.

Kamete AY (2007) Cold-hearted, negligent and spineless? Planning, planners and the (r)ejection of 'filth' in urban Zimbabwe. International Planning Studies 12(2):153-171.

Kamete AY (2008) Planning versus youth: stamping out spatial unruliness in Harare. Geoforum 3(5):1721-33.

Kamete AY (2009) In the service of tyranny: Debating the role of planning in Zimbabwe's urban 'clean-up' operation. Urban Studies 46(4):897-922.

Kamete AY (2013) On handling urban informality in southern Africa. Geografiska Annaler: Series B, Human Geography 95(1):17-31.

Kamete AY (2016) 'Programmed to serve': Urban planning and elite interests in Zimbabwe. In: Silva CN (ed) Governing Urban Africa. London: Palgrave Macmillan, pp. 151-169

Kamete AY (2017) Pernicious assimilation: Reframing the integration of the urban informal economy in southern Africa. Urban Geography 39(2):167-189.

Lefebvre H (1991) The Production of Space (Trans. D. Nicholson-Smith). Oxford: Blackwell. 
Lutzoni L (2016) In-formalised urban space design: Rethinking the relationship between formal and informal. City, Territory and Architecture 3(1):3-20.

Månsson N (2008) Bauman on strangers: unwanted peculiarities. In: Jacobsen HM and Poder P (eds) The Sociology of Zygmunt Bauman: Challenges and Critique. London: Ashgate, pp. $155-171$.

Marotta V (2002) Zygmunt Bauman: Order, strangerhood and freedom. Thesis Eleven 70(1):3654.

Moran LJ and Skeggs B (2004) Sexuality and the Politics of Violence and Safety. London: Routledge.

MSMED (Ministry of Small and Medium Enterprises Development) (2007) Mission Statement. Available at: http://www.msmed.gov.zw/The\%20Ministry/about.htm (accessed 4 August 2007).

MYDEC (Ministry of Youth Development and Employment Creation) (undated) Employment Creation Department programmes. Available at: http://www.mydgec.gov.zw/eprogrammes.htm (accessed 7 August 2007).

Njoh AJ (2006) Planning Power: Town Planning and Social Control in Colonial Africa. London: UCL Press.

Noble G (2005) The discomfort of strangers: Racism, incivility and ontological security in a relaxed and comfortable nation. Journal of Intercultural Studies 26(1-2):107-120.

Phelan S (2001) Sexual Strangers: Gays, Lesbians, and Dilemmas of Citizenship. Philadelphia: Temple University Press.

Pickering M (2001) Stereotyping: The Politics of Representation. Basingstoke: Palgrave Pile S (1997) Introduction: Opposition, political identities and spaces of resistance. In: Pile S and Keith M (eds) Geographies of Resistance. London: Routledge, pp. 1-32.

Potts D (2006) 'Restoring order'? Operation Murambatsvina and the urban crisis in Zimbabwe. Journal of Southern African Studies 32(2):273-291. 
Potts D (2008) The urban informal sector in sub-Saharan Africa: From bad to good (and back again?). Development Southern Africa 25 (2):151-167.

Rumford C (2016) The Globalization of Strangeness. Basingstoke: Palgrave Macmillan.

Sandercock L (2000) When strangers become neighbours: Managing cities of difference. Planning Theory and Practice 1(1):13-30.

Sanyal R (2014) Urbanizing refuge: Interrogating spaces of displacement. International Journal of Urban and Regional Research 38(2):558-572.

Segal S (1998) The anxiety of strangers and the fear of enemies. Studies in Philosophy and Education 17(4):271-282.

Shields R (undated) Henri Lefebvre: Introduction. Available at: www.ualberta.ca/ rshields/f/lecture.ppt (accessed 14/06/2013).

Yiftachel O (2002) The dark side of modernism: Planning as control of an ethnic minority. In: Bridge G and Watson S (eds) The Blackwell City Reader. Oxford: Blackwell, pp. 535-541.

Yiftachel O (2009a) Theoretical notes on 'gray cities': The coming of urban apartheid? Planning Theory 8(1):88-100

Yiftachel O (2009b) Critical theory and 'gray space': Mobilization of the colonized. City, 13(23):246-263.

Yiftachel O (2015) Epilogue_-from 'gray space' to equal 'metrozenship'? Reflections on urban citizenship. International Journal of Urban and Regional Research 39(4):726-737. 